\title{
Pregnancy-Induced Hypertension in North Carolina, 1988 and 1989
}

\section{$\begin{array}{lllllllll}\text { A } & \text { B } & \mathbf{S} & \mathbf{T} & \mathbf{R} & \mathbf{A} & \mathbf{C} & \mathbf{T}\end{array}$}

Introduction. Pregnancy-induced hypertension (PIH) is a highly prevalent pregnancy complication with adverse effects on maternal and infant health. Epidemiologic research concerning its etiology is limited.

Methods. Birth records from North Carolina for the period 1988 through 1989 include an indication of the presence of PIH. The risk of PIH was examined in relation to several maternal characteristics and exposures, including reproductive history, demographic characteristics, and tobacco use during pregnancy. Risk ratio estimates, adjusted for confounders, were calculated contrasting PIH among exposed vs unexposed women.

Results. The overall risk of PIH was 43.1 per 1000 births, with multiple pregnancies, nulliparity, and advanced maternal age associated with markedly increased risks. Tobacco use was inversely associated with PIH, and Blacks and Whites were at virtually equal risk.

Conclusions. Problems in diagnosis and classification impede research in this area, with birth certificates limited in quality and breadth of information. Nonetheless, several patterns emerged that are worthy of further epidemiologic evaluation using more sophisticated designs. (Am J Public Health 1992;82:675-679)

David A. Savitz, PhD, and Jun Zhang, MB

\section{Introduction}

Pregnancy-induced hypertension (PIH) is among the most common pregnancy complications, with a cumulative incidence estimated as high as 7\%,1,2 $\mathrm{PIH}$ is associated with a substantial increase in growth retardation and preterm birth and threatens the life of the mother if untreated. ${ }^{3}$ Classification of PIH remains controversial, but most authorities recognize that (1) preexisting hypertension and hypertension developing during labor are distinct from hypertension developing during pregnancy ${ }^{4}$ and (2) preeclampsia, in which the blood pressure elevation is accompanied by proteinuria or edema, is distinct from gestational hypertension alone. 5 Nonetheless, the common occurrence of edema in late pregnancy and frequent difficulty in accurately separating preeclampsia from isolated gestational hypertension ${ }^{4}$ make PIH a suitable entity for etiologic research, while recognizing that there are likely to be heterogeneous subcategories present. 6

There has been limited research into the etiology of PIH, in spite of its frequency. Primiparas are known to be at markedly greater risk of preeclampsia than multiparas. ${ }^{7}$ Women who smoke cigarettes have been reported to show a reduced risk of preeclampsia.8,9 Elevated blood lead levels, ${ }^{10}$ exposure to organic solvents, ${ }^{11}$ lack of leisure-time physical activity early in pregnancy, 12 male fetuses, ${ }^{13}$ low levels of calcium intake, ${ }^{14}$ use of barrier contraceptives, 15 and young maternal age ${ }^{16}$ have all been reported to increase the risk of PIH or preeclampsia, but these observations await corroboration or refutation. These clues deserve follow-up in focused studies, yet additional analyses that simply describe the patterns of occurrence in defined populations are also needed. Even such basic questions as the presence of racial differences in risk have not been resolved. ${ }^{16}$ The modification of the North Carolina birth certificate in 1988 to include a checklist item for PIH, as well as several risk factors of potential interest (e.g., cigarette smoking), provides an efficient opportunity to examine patterns of PIH among women in the state.

\section{Methods}

Birth data for North Carolina for the years 1988 and 1989 were made available from the Center for Health and Environmental Statistics of the North Carolina Department of Environment, Health, and Natural Resources. A nurse or clerk in the hospital of delivery completes a certificate of live birth, which includes the usual array of demographic and residential information as well as a series of health conditions in check-box format. Three items from the birth certificate were used in this analysis: "hypertension, chronic"; "hypertension, pregnancy-associated"; and "eclampsia." This information is obtained from the medical record subsequent to delivery, with no formal quality-control procedures. Nonetheless, the clinical significance of these events makes them likely to be noted with some accuracy and prominence in the charts. Additional items used in the analysis were mother's age, moth-

The authors are with the Department of Epidemiology, School of Public Health, University of North Carolina at Chapel Hill and the Carolina Population Center.

Requests for reprints should be sent to David A. Savitz, PhD, Department of Epidemiology, CB \#7400, School of Public Health, University of North Carolina, Chapel Hill, NC 27599-7400.

This paper was submitted to the Journal September 30, 1991, and accepted with revisions December 10, 1991. 
er's education (in years), child's race (Black, White, other), child's sex, gravidity, parity, plurality (singleton, multiple birth), onset of prenatal care, tobacco use (cigarettes per day), gestational age, birthweight, weight gain during pregnancy, mother's residence (urban/rural, Coastal Plain vs other), and month and season of birth. Although information on alcohol use is requested, the very small number of women who were reported to have used alcohol during pregnancy $(2.6 \%)$ suggests that the information is unsuitable for analysis.

Starting with a total of 199651 live births to residents of North Carolina, women with missing data on PIH ( $n=1636)$, preexisting hypertension present $(n=1869)$, or missing data on preexisting hypertension $(n=1636)$ were omitted (some women having more than one exclusion criterion), leaving 196146 births for analysis. Risk among women with multiple as compared with singleton gestations differed markedly (80.6 per 1000 vs 42.2 per 1000 , respectively), so women with multiple fetuses $(n=4527)$ were omitted from the main analyses. Absence of prenatal care was associated with reduced incidence of PIH (risks of 43.4 per 1000 and 22.4 per 1000 , respectively). This pattern is presumably due to lack of opportunity for diagnosis, so that women with no prenatal care or with missing data on the onset of prenatal care were also omitted ( $n=3975)$. This left 187742 women (91 188 in 1988 and 96554 in 1989) with information on PIH, known absence of preexisting hypertension, singleton gestations, and known initiation of prenatal care prior to delivery. PIH was defined as an indication of either "hypertension, pregnancy-associated" or "eclampsia." By definition, eclampsia must be preceded by preeclampsia.4,6

Risks of PIH were calculated per 1000 live births by dividing number of PIH cases by the total number of births in the stratum. We examined risk by calendar year, season, and geographic area in the state (focusing on urban-rural gradients and residence in the Coastal Plain). Demographic characteristics of interest included mother's race (White, Black, other), mother's and father's age, and mother's education. Races other than Black and White were too diverse for analysis, with small numbers of American Indians $(2.5 \%$ of births), Filipinos (0.5\% of births), and other Asian or Pacific Islanders $(0.3 \%$ of births) and a smaller number of Chinese, Japanese, and Hawaiians.
Gravidity and parity were examined as indicators of reproductive history. Attributes of the present pregnancies included infant sex, timing of prenatal care onset, smoking during pregnancy, and potential consequences of $\mathrm{PIH}$, including weight gain during pregnancy, gestational age at delivery, and birthweight.

Crude risks and risk ratios were calculated and adjusted odds ratios (ORs) obtained by Mantel-Haenzel adjustment and logistic regression. ${ }^{17} \mathrm{PIH}$ is sufficiently rare in this population (under 5\%) that risk ratios and ORs would be similar in magnitude.

\section{Results}

For the period 1988 through 1989, the risk of PIH in North Carolina was 43.1 per thousand. Although lower than is often reported, this highly prevalent problem affected over 4200 women in the state each year. Risks were similar over the 2 years, with women delivering in the summer or fall at somewhat lower risk than those delivering in the winter or spring (40.3 and 46.1 per thousand, respectively).

Table 1 presents crude risk ratios and risk ratios adjusted for parity, with $95 \%$ confidence intervals (CIs). Dividing the state's population by community size yielded indications of a slightly higher risk in the most rural areas. Comparison of the Coastal Plain with the remainder of the state (data not shown) identified no gradient in PIH risk (adjusted OR $=1.0,95 \%$ $\mathrm{CI}=1.0-1.1$ ).

A monotonically increasing risk of PIH was observed in relation to maternal age, with a twofold difference between the youngest $(<20)$ and oldest $(40+)$ mothers. Little difference was found across levels of maternal education, with a slight decrease in risk for women with 16 or more years of education. Blacks and Whites had similar PIH risks, with other races slightly lower. Infant sex was unrelated to PIH.

Gravidity and parity showed the most pronounced patterns: first pregnancies and births had double the risk of PIH compared with subsequent ones, with no evidence of a dose-response gradient after the first. Slight indications of a rising risk beyond parity 3 were observed. Among nulliparous women, there was no effect of differing gravidity: there was a relative risk of 1.0 for nulliparous women with previous pregnancies compared with those without previous pregnancies. Among mothers who received prenatal care, there were no differences in relation to the trimester in which care was begun.
Crude results for tobacco use showed an inverse gradient with PIH risk, which was diminished by adjustment for parity. Even after adjustment, however, there was a monotonically decreasing risk, with increasing amount smoked culminating in an adjusted risk ratio of 0.7 in women smoking 20 or more cigarettes per day.

Pronounced associations were found between PIH and reduced gestational age, reduced birthweight, and increased weight gain during pregnancy. These are not thought to be pertinent to the etiology of PIH; rather, they are presumably a reflection of the disease itself (increased weight gain due to edema) or the consequences of PIH (gestational age, birthweight).

Variables that were found to be associated with PIH (parity, mother's age, smoking during pregnancy) and others of a priori interest (race, mother's education) were examined simultaneously in a logistic regression model (Table 2). The results were generally consistent with the parityadjusted risk ratios. Nulliparity remained strongly associated with increased risk. Blacks and Whites were indistinguishable in risk, with other races at lower risk. Older maternal age was associated with increased PIH risk, and education above 16 years was associated with decreased risk. Prenatal care onset was still essentially unrelated to PIH. Smoking's association with reduced risk was not affected by adjustment.

Separate logistic regression analyses for Blacks and Whites yielded similar patterns, except that the increased risk with advanced maternal age was stronger among Blacks and the benefits of high levels of education were stronger among Whites (Table 2).

Results were also compared for women of parity $0 \mathrm{vs}$ women of parity $1+$ (Table 2). The increased risk of PIH with increased maternal age was notably weaker among nulliparous women but was still apparent. Otherwise, the pattern of risk factors among the two parity groups was quite similar.

\section{Discussion}

The overall risk of PIH found in this analysis of North Carolina birth certificates (43.1 per 1000 singleton live births) is slightly lower than has been reported in the literature 2 but compatible with recent estimates of 26 per 1000 births for preeclampsia. ${ }^{16}$ There is substantial confusion due to inconsistent terminology and diagnostic inaccuracies among preexisting 
TABLE 1-Crude and Adjusted Risk Ratios for PIH in Relation to Demographic Characteristics, Reproductive History, Behaviors during Pregnancy, and Pregnancy Outcome: North Carolina, 1988-1989

\begin{tabular}{|c|c|c|c|c|c|c|}
\hline & $\begin{array}{l}\text { No. of } \\
\text { Cases }\end{array}$ & $\begin{array}{l}\text { No. of } \\
\text { Births }\end{array}$ & Risk & $\begin{array}{l}\text { Crude Risk } \\
\text { Ratio }\end{array}$ & $\begin{array}{l}\text { Adjusted } \\
\text { Risk Ratio }^{\mathrm{a}}\end{array}$ & $\begin{array}{l}95 \% \text { Confidence } \\
\text { Interval }\end{array}$ \\
\hline \multicolumn{7}{|l|}{ Community population } \\
\hline Rural & 4670 & 102162 & 45.7 & 1.0 & 1.0 & \\
\hline $2500-4999$ & 433 & 9928 & 43.6 & 1.0 & 1.0 & $0.9-1.1$ \\
\hline $5000-9999$ & 360 & 9621 & 37.4 & 0.8 & 0.8 & $0.7-0.9$ \\
\hline $10000-24999$ & 626 & 14585 & 42.9 & 0.9 & 0.9 & $0.9-1.0$ \\
\hline $25000-49999$ & 341 & 10404 & 32.8 & 0.7 & 0.7 & $0.6-0.8$ \\
\hline $50000+$ & 1563 & 41042 & 38.1 & 0.8 & 0.8 & $0.8-0.9$ \\
\hline \multicolumn{7}{|l|}{ Mother's age, $y$} \\
\hline$<20$ & 1522 & 30278 & 50.3 & 1.2 & 0.9 & $0.9-1.0$ \\
\hline $20-29$ & 4655 & 113053 & 41.2 & 1.0 & 1.0 & ... \\
\hline $30-34$ & 1241 & 32593 & 38.1 & 0.9 & 1.1 & $1.0-1.2$ \\
\hline $35-39$ & 473 & 9946 & 47.6 & 1.2 & 1.5 & $1.3-1.6$ \\
\hline $40+$ & 72 & 1281 & 56.2 & 1.4 & 1.9 & $1.5-2.4$ \\
\hline \multicolumn{7}{|l|}{ Mother's education, $y$} \\
\hline$<9$ & 257 & 6137 & 41.9 & 0.9 & 0.9 & $0.8-1.0$ \\
\hline $9-11$ & 1486 & 36498 & 40.7 & 0.9 & 0.9 & $0.8-0.9$ \\
\hline 12 & 3506 & 77705 & 45.1 & 1.0 & 1.0 & $\ldots$ \\
\hline $13-15$ & 1614 & 35823 & 45.1 & 1.0 & 1.0 & $0.9-1.1$ \\
\hline $16+$ & 1122 & 31327 & 35.8 & 0.8 & 0.8 & $0.7-0.8$ \\
\hline \multicolumn{7}{|l|}{ Child's race } \\
\hline White & 5560 & 127708 & 43.5 & 1.0 & 1.0 & \\
\hline Black & 2265 & 54655 & 41.4 & 1.0 & 1.0 & $1.0-1.0$ \\
\hline Other & 168 & 5379 & 31.2 & 0.7 & 0.7 & $0.6-0.9$ \\
\hline \multicolumn{7}{|l|}{ Child's sex } \\
\hline Male & 4153 & 95816 & 43.3 & 1.0 & 1.0 & \\
\hline Female & 3840 & 91926 & 41.8 & 1.0 & 1.0 & $0.9-1.0$ \\
\hline \multicolumn{7}{|l|}{ Gravidity } \\
\hline $\begin{array}{l}0 \\
1\end{array}$ & $\begin{array}{l}4383 \\
1948\end{array}$ & $\begin{array}{l}71185 \\
5921 ?\end{array}$ & 61.6 & 1.0 & ... & \\
\hline 2 & $\begin{array}{r}1948 \\
915\end{array}$ & $\begin{array}{l}59212 \\
32548\end{array}$ & $\begin{array}{l}32.9 \\
28.1\end{array}$ & $\begin{array}{l}0.5 \\
0.5\end{array}$ & $\cdots$ & $\begin{array}{l}0.5-0.6^{b} \\
0.4-0.5\end{array}$ \\
\hline 3 & 405 & 14445 & 28.0 & 0.5 & $\ldots$ & 0.40 .5 \\
\hline $4+$ & 330 & 10036 & 32.9 & 0.5 & ... & $0.5-0.6$ \\
\hline \multicolumn{7}{|l|}{ Parity } \\
\hline 0 & 5342 & 87360 & 61.1 & 1.0 & ... & $\ldots$ \\
\hline 1 & 1716 & 63474 & 27.0 & 0.4 & $\ldots$ & $0.40 .5^{b}$ \\
\hline 2 & 619 & 25863 & 23.9 & 0.4 & ... & $0.3-0.4$ \\
\hline 3 & 202 & 7622 & 26.5 & 0.4 & ... & $0.4-0.5$ \\
\hline $4+$ & 114 & 3374 & 33.8 & 0.6 & ... & $0.5-0.7$ \\
\hline \multicolumn{7}{|c|}{ Prenatal care onset, mo } \\
\hline $1-3$ & 6328 & 144395 & 43.8 & 1.0 & 1.0 & ... \\
\hline $4-6$ & 1389 & 35788 & 38.8 & 0.9 & 0.9 & $0.9-1.0$ \\
\hline $7-9$ & 276 & 7569 & 36.5 & 0.8 & 0.9 & $0.8-1.0$ \\
\hline \multicolumn{7}{|c|}{$\begin{array}{l}\text { Tobacco use during pregnancy, no. of } \\
\text { cigarettes per day }\end{array}$} \\
\hline 0 & 6604 & 148345 & 44.5 & 1.0 & 1.0 & \\
\hline $1-9$ & 359 & 9460 & 37.9 & 0.9 & 0.9 & $0.8-1.0$ \\
\hline $10-19$ & 459 & 14307 & 32.1 & 0.7 & 0.8 & $0.7-0.8$ \\
\hline $20+$ & 369 & 12950 & 28.5 & 0.6 & 0.7 & $0.7-0.8$ \\
\hline $\begin{array}{l}\text { Amount unknown } \\
\text { Gestational age, wk }\end{array}$ & 129 & 3496 & 36.9 & 0.8 & 0.9 & $0.7-1.0$ \\
\hline \multicolumn{7}{|l|}{ Gestational age, wk } \\
\hline $37-41$ & 5955 & 142671 & 41.7 & $\begin{array}{l}7.4 \\
1.0\end{array}$ & $\begin{array}{l}1.4 \\
1.0\end{array}$ & \\
\hline $42+$ & 913 & 25378 & 36.0 & 0.9 & 0.8 & $0.8-0.9$ \\
\hline \multicolumn{7}{|l|}{ Birthweight, $g$} \\
\hline$<1500$ & 191 & 2152 & 88.8 & 2.4 & 2.3 & $2.0-2.6$ \\
\hline $1500-2500$ & 828 & 9962 & 83.1 & 2.2 & 2.2 & $2.0-2.3$ \\
\hline $2501-3000$ & 1397 & 30476 & 45.8 & 1.2 & 1.2 & $1.1-1.3$ \\
\hline $3001-3500$ & 2587 & 69675 & 37.1 & 1.0 & 1.0 & $\ldots$ \\
\hline $3501-4000$ & 2121 & 55190 & 38.4 & 1.0 & 1.1 & $1.0-1.1$ \\
\hline $\begin{array}{l}4001+ \\
\text { Weight gain, ib }\end{array}$ & 868 & 20168 & 43.0 & 1.2 & 1.2 & $1.1-1.3$ \\
\hline $\begin{array}{l}\text { Weight gain, lb } \\
0-20\end{array}$ & \multicolumn{3}{|c|}{ Weight gain, lb } & 0.9 & 1.0 & $0.9-1.1$ \\
\hline $21-40$ & 4213 & 110180 & 38.2 & 1.0 & 1.0 & \\
\hline $41-60$ & 1608 & 24083 & 66.8 & 1.7 & 1.6 & $1.5-1.7$ \\
\hline $61+$ & 278 & 2274 & 122.3 & 3.2 & 2.9 & $2.6-3.2$ \\
\hline $\begin{array}{l}\text { Note. PIH = pregnan } \\
\text { multiple gestation; a } \\
\text { aAdjusted for parity (1 } \\
{ }^{\circ} \text { Confidence intervals }\end{array}$ & deds wi & data 0 & preexi & tension, o & are; pree & tension present; \\
\hline
\end{tabular}


Table 2-Results of Logistic Regression of Pregnancy-Induced Hypertension by Race and Parity: North Carolina, 1988-1989

\begin{tabular}{|c|c|c|c|c|c|c|c|c|c|c|}
\hline & \multicolumn{2}{|c|}{ Total } & \multicolumn{2}{|c|}{ Whites } & \multicolumn{2}{|c|}{ Blacks } & \multicolumn{2}{|c|}{ Parity 0} & \multicolumn{2}{|c|}{ Parity $1+$} \\
\hline & $\begin{array}{l}\text { Adjusted } \\
\text { Odds } \\
\text { Ratio }\end{array}$ & $\begin{array}{l}95 \% \\
\text { Confidence } \\
\text { Interval }\end{array}$ & $\begin{array}{l}\text { Adjusted } \\
\text { Odds } \\
\text { Ratio }\end{array}$ & $\begin{array}{c}95 \% \\
\text { Confidence } \\
\text { Interval }\end{array}$ & $\begin{array}{l}\text { Adjusted } \\
\text { Odds } \\
\text { Ratio }\end{array}$ & $\begin{array}{c}95 \% \\
\text { Confidence } \\
\text { Interval }\end{array}$ & $\begin{array}{l}\text { Adjusted } \\
\text { Odds } \\
\text { Ratio }\end{array}$ & $\begin{array}{c}95 \% \\
\text { Confidence } \\
\text { Interval }\end{array}$ & $\begin{array}{l}\text { Adjusted } \\
\text { Odds } \\
\text { Ratio }\end{array}$ & $\begin{array}{l}95 \% \\
\text { Confidence } \\
\text { Interval }\end{array}$ \\
\hline Parity $(1+$ vs 0$)$ & 0.4 & $0.3-0.4$ & 0.4 & $0.3-0.4$ & 0.4 & $0.3-0.5$ & 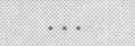 & $\cdots$ & $\cdots$ & $\ldots$ \\
\hline \multicolumn{11}{|l|}{ Race } \\
\hline Black vs White & 1.0 & $0.9-1.0$ & $\ldots$. & $\ldots$ & $\ldots$ & $\ldots$ & 0.9 & $0.8-1.0$ & 1.1 & $1.0-1.2$ \\
\hline Other vs White & 0.7 & $0.6-0.9$ & ... & $\ldots$ & .... & $\ldots$ & 0.7 & $0.5-0.9$ & 0.7 & $0.5-1.0$ \\
\hline \multicolumn{11}{|l|}{ Mother's age, $y$} \\
\hline$<20$ vs $20-34$ & 0.9 & $0.8-0.9$ & 0.9 & $0.8-1.0$ & 0.9 & $0.7-1.0$ & 1.0 & $0.8-1.0$ & 0.5 & $0.4-0.7$ \\
\hline $\begin{array}{c}35+\text { vs } 20-34 \\
\text { Mother's educatior }\end{array}$ & Mother's education, y & $1.4-1.8$ & 1.4 & $1.2-1.6$ & 2.1 & $1.7-2.5$ & 1.3 & $1.0-1.5$ & 1.8 & $1.6-2.0$ \\
\hline$<12$ vs $12-15$ & 1.0 & $0.9-1.1$ & 1.0 & $0.9-1.1$ & 1.0 & $0.8-1.1$ & 1.0 & $0.9-1.1$ & 1.1 & $0.9-1.2$ \\
\hline $\begin{array}{l}16+\text { vs } 12-15 \\
\text { Prenatal care onse }\end{array}$ & 0.7 & $0.6-0.7$ & 0.7 & $0.6-0.7$ & 0.9 & $0.7-1.0$ & 0.7 & $0.6-0.8$ & 0.6 & $0.5-0.7$ \\
\hline $4-6$ vs $1-3$ & 0.9 & $0.8-1.0$ & 0.9 & $0.8-1.0$ & 1.0 & $0.8-1.1$ & 0.9 & $0.8-1.0$ & 0.9 & $0.8-1.0$ \\
\hline $7-9$ vs $1-3$ & 0.9 & $0.8-1.0$ & 0.9 & $0.7-1.0$ & 1.0 & $0.8-1.2$ & 1.0 & $0.8-1.2$ & 0.8 & $0.6-1.0$ \\
\hline \multicolumn{11}{|c|}{$\begin{array}{l}\text { Tobacco use during } \\
\text { pregnancy, no. of } \\
\text { cigarettes per day }\end{array}$} \\
\hline $1-9$ & 0.9 & $0.7-1.0$ & 0.9 & $0.7-1.0$ & 0.8 & $0.6-1.0$ & 0.8 & $0.7-1.0$ & 0.9 & $0.7-1.1$ \\
\hline $10-19$ & 0.7 & $0.6-0.8$ & 0.7 & $0.6-0.8$ & 0.7 & $0.5-0.9$ & 0.7 & $0.6-0.8$ & 0.8 & $0.6-0.9$ \\
\hline $20+$ & 0.7 & $0.6-0.8$ & 0.7 & $0.5-0.8$ & 0.8 & $0.5-1.0$ & 0.7 & $0.6-0.8$ & 0.6 & $0.5-0.7$ \\
\hline
\end{tabular}

chronic hypertension, preeclampsia, and other forms of PIH that makes comparisons among studies difficult. Several papers have recently proposed standardized classification systems, ${ }^{4-6}$ but at present these more refined classifications are not available for large populations.

The literature with which the patterns of PIH found in North Carolina can be compared is quite limited. An examination of patterns of hospitalized cases of preeclampsia found increased risk with young maternal age (in contrast to the opposite pattern reported here), although similar risks for Blacks and Whites were found in both studies. ${ }^{16}$ The well-recognized increased risk of preeclampsia for nulliparas and plural gestations ${ }^{7}$ was clearly identified in our data. Chesley cites "conventional wisdom" that Blacks are at greater risk of preeclampsia than Whites and that lower social class women are at greater risk than upper social class women, which he challenges for the absence of evidence. ${ }^{7}$ The present data indicate the absence of such racial or social class differences, with a suggestion only of lower risk among women who are neither Black nor White.

The inverse association between cigarette smoking and $\mathrm{PIH}$ has been reported previously. ${ }^{8,9}$ Marcoux et al. separated preeclampsia from other forms of PIH and found the strongest inverse association with preeclampsia, with risks of $0.8,0.6$, and 0.4 for smokers of less than 11,11 to
20 , and 20 or more cigarettes per day. ${ }^{9}$ The present study found more modest reductions in risk of $0.9,0.8$, and 0.7 for similar smoking categories but combining all forms of PIH. Generally, the results of the two studies are similar given the weaker smoking gradient found by Marcoux et al. for PIH other than preeclampsia. The quality of smoking data on birth certificates is questionable, given the stigma associated with smoking during pregnancy, but nondifferential misclassification seems most probable with a resulting bias toward the null. ${ }^{17}$ If the reporting were biased, one would expect overreporting for women with adverse outcomes (i.e., PIH) relative to women with uncomplicated pregnancies, opposite to the observed inverse association.

The limitations in the data should be acknowledged. The principal concern is in the undocumented process by which diagnoses of PIH are made. The process by which a woman comes to be documented on the birth certificate as having PIH involves many steps, including her entry into prenatal care, diagnosis by a physician, notation in the medical record, and transfer of that information to the birth certificate. Each step is potentially fallible, with underascertainment likely. Nonetheless, the overall risk of reported PIH seems reasonable, and the corroboration of previously recognized patterns by parity and cigarette smoking provides some reassurance regarding the quality of the data.

In spite of the virtually universal adoption of the new birth certificate format, there has been little work done to empirically assess the validity of its contents. To our knowledge, the only directly applicable study was a comparison in the state of Missouri between the risk of PIH based on the birth certificate item and the risk based on hospital discharge data (W. Schramm, written communication, May 1991). There were 42.5 cases per 1000 births based on hospital discharge data vs 36.1 cases per 1000 births based on the birth certificate information, resulting in a ratio of 0.85 . This would suggest modest underascertainment on birth certificates, but the actual sensitivity and specificity of classification could not be estimated. Research is badly needed to evaluate the quality of specific items on the certificate so that researchers and health care planners can make appropriate use of what will soon be widely available data. Studies of pregnancy and delivery complications other than PIH in Washington State indicate that the check-box format yields more complete reporting than an openended format. 18

A second limitation of this study is that it was not possible to separate PIH into true preeclampsia (hypertension with proteinuria or edema) and other forms of PIH for separate analyses. It was, however, possible to remove women with re- 
ported chronic hypertension from the analysis. To the extent that the subtypes of PIH have distinct etiologies, the results reported here are diluted.

Finally, there was a limited array of information available from the birth certificate for analysis and, for at least some of the items, questions about data quality arise. Hypotheses regarding the role of nutrition and contraception, for example, could not be addressed at all. Alcohol use was judged to be inadequately reported for analysis, based on the rarity of reported use. Many of the demographic characteristics (mother's age, education, parity, etc.) are thought to be well reported. Although tobacco smoking as reported on the birth certificate has not been validated, a study in Missouri suggested that the aggregate levels are concordant with those obtained in the National Natality Survey. ${ }^{19,20}$ The sample included in the National Natality Survey differs markedly from the North Carolina population with regard to race and marital status, but some reassurance of reasonable data quality is provided by the observation of similar patterns in the two sources (including comparable overall prevalence, reduced smoking during pregnancy with advancing age, and a marked reduction with increasing levels of education). Furthermore, recent analysis of North Carolina birth certificate data ${ }^{21}$ revealed the usual pattern of reduced birthweight among smokers, providing additional assurance about the quality of that item.

The pattern of results supports further epidemiologic evaluation of this highly prevalent and etiologically mysterious condition. Perhaps the associations not found are as important as those that were: race and social class were virtually unrelated to risk except for a reduced risk among women of "other" races. This might suggest the absence of environmen- tal influences, but the clear patterns by maternal age, parity, and tobacco use indicate otherwise. Weaker associations were found with season of birth (higher risks for winter and spring births) and increased risk with the most rural residence. With the recent availability of information on PIH in vital records, broader geographic areas should be examined to develop refined etiologic hypotheses in parallel with more focused studies of existing hypotheses.

\section{Acknowledgments}

We would like to thank Paul Buescher, $\mathrm{PhD}$, for his assistance in obtaining and interpreting the data and for his thorough and constructive review of the manuscript. We would also like to acknowledge the advice on disease classification provided by Watson Bowes III, MD.

\section{References}

1. Lindmark G, Lindberg B, Hogstedt S. The incidence of hypertensive disease in pregnancy. Acta Obstet Gynecol Scand Suppl. 1984;118:29-32.

2. Sullivan JM. Hypertension in Pregnancy. Chicago, Ill: Year Book Medical Publishers; 1986:3-7.

3. Davies AM, Dunlop W. Hypertension in pregnancy. In: Barron SL, Thomson AM, eds. Obstetrical Epidemiology. London: Academic Press. 1983:167-208.

4. Davey DA, MacGillivray I. The classification and definition of the hypertensive disorders of pregnancy. AmJ Obstet Gynecol. 1988;158:892-898.

5. Lindheimer MD, Katz AI. Hypertension in pregnancy. N Engl J Med. 1985;313:675680.

6. Anonymous. Classification of hypertensive disorders of pregnancy. Lancet. 1989;1:935-936.

7. Chesley LC. History and epidemiology of preeclampsia-eclampsia. Clin Obstet Gynecol. 1984;27:801-820.

8. Duffus GM, MacGillivray I. The incidence of pre-eclamptic toxaemia in smokers and non-smokers. Lancet. 1968;1:994-995.

9. Marcoux S, Brisson J, Fabia J. The effect of cigarette smoking on the risk of preec- lampsia and gestational hypertension. Am J Epidemiol. 1989;130:950-957.

10. Rabinowitz M, Bellinger D, Leviton A, Needleman H, Schoenbaum S. Pregnancy hypertension, blood pressure during labor, and blood lead levels. Hypertension. 1987;10:447-451.

11. Eskenazi B, Bracken MB, Holford TR, Grady J. Exposure to organic solvents and hypertensive disorders of pregnancy. Am J Ind Med. 1988;14:177-188.

12. Marcoux S, Brisson J, Fabia J. The effect of leisure time physical activity on the risk of pre-eclampsia and gestational hypertension. J Epidemiol Community Health. 1989;43:147-152.

13. Campbell DM, MacGillivray I. Pre-eclampsia in second pregnancy. BrJ Obstet Gynecol. 1985;92:131-140.

14. Belizan JM, Villar J, Repke J. The relationship between calcium intake and pregnancyinduced hypertension: up-to-date evidence. Am J Obstet Gynecol. 1988;158:898-902.

15. Klonoff-Cohen H, Savitz DA, Cefalo RC, McCann MF. An epidemiologic study of preeclampsia.JAMA. 1989;262:2143-2147.

16. Saftlas AF, Olson DR, Franks AL, Atrash HK, Pokras R. Epidemiology of preeclampsia and eclampsia in the United States, 1979-1986. Am J Obstet Gynecol. 1990;163: $460-465$.

17. Rothman KJ. Modem Epidemiology. Boston, Mass: Little, Brown; 1986.

18. Frost F, Starzyk P, George S, McLaughlin JF. Birth complication reporting: the effect of birth certificate design. Am J Public Health. 1984;74:505-506.

19. Stockbauer JW, Land GH. Changes in characteristics of women who smoke during pregnancy: Missouri, 1978-88. Public Health Rep. 1991;106:52-58.

20. Prager K, Malin H, Spiegler D, Van Natta P, Placek PJ. Smoking and drinking behavior before and during pregnancy of married mothers of live-born infants and stillborn infants. Public Health Rep. 1984;99:117 127.

21. Buescher PA. New Items on the North Carolina Birth Certificate. Raleigh, NC: Division of Statistics and Information Services, Center for Health and Environmental Statistics, North Carolina Department of Environment, Health, and Natural Resources; 1991. CHES Studies Report No. 58. 